\title{
MUERTES DE AURORA: EL ÁNGEL CAÍDO DE LA HISTORIA O LA MEMORIA DELIRANTE
}

\author{
POR \\ Aurelia Gómez Unamuno \\ Haverford College
}

Articular históricamente lo pasado

no significa conocerlo "tal y como verdaderamente ha sido".

Significa adueñarse de un recuerdo

tal y como relumbra en el instante de un peligro.

Walter Benjamin

Con todo, el 68 no desaparece,

es la referencia interminable,

el rito de tránsito de una generación

que al evocarlo habita su "Edad de Oro",

la demanda de justicia que siempre comienza

porque nunca es atendida.

Yle toca a los escritores y al grupo de ex presos políticos insistir en lo no mítico del 68:

la impunidad de los victimarios.

Carlos Monsiváis

Durante las últimas décadas, ha habido un creciente interés en la reflexión sobre el pasado, particularmente si éste ha sido violento y ha dejado marcas y heridas que difícilmente han sanado en el cuerpo social. En México, la represión del 2 de octubre de 1968 en Tlatelolco, si bien no fue la única ni la primera pero sí la más emblemática, produjo posteriormente un ciclo de narrativa y poesía que fundamentalmente se centró en el repudio a la masacre. La inmediatez por denunciar la violencia del Estado, pero sobre todo la impunidad, como conmina Carlos Monsiváis en el epígrafe, han resultado en la producción de textos literarios y testimoniales que, poniendo el dedo en la llaga, evocan el movimiento estudiantil y en particular su trágica represión en Tlatelolco. Aunque la mayoría de los textos de esta 'narrativa tlatelolca', como la ha llamado Aralia López, aparecen en la década de los setenta y ochenta, posteriormente en la década de los noventa y dos mil algunas novelas han retomado el tema. 
Este artículo plantea de manera general ciertas problemáticas en torno a la escritura del pasado, el modo en que se ha construido la memoria del 68 mexicano y la mirada alternativa que plantea la novela Muertes de Aurora (1980) de Gerardo de la Torre en relación a la tendencia general de este ciclo. En lugar de reconstruir minuciosamente la tarde del 2 de octubre, Muertes de Aurora centra su atención en la incipiente participación de los trabajadores petroleros en el movimiento del 68, destacando críticamente la problemática sindical como resultado de la corrupción y cooptación del gobierno priísta, así como la gran derrota del movimiento obrero de 1958. Bajo una perspectiva crítica de la Torre presenta la cita (im)posible entre el sector universitario y el obrero, destacando las tensiones entre ambos y cuestionando a la cultura letrada. A partir de una mirada marginal articulada en el personaje protagonista Jesús de la Cruz, desempleado y alcohólico, Gerardo de la Torre aborda a la memoria de violencia como una aparición recurrente en la forma de esperanza y fantasmagoría que irrumpe con el continuum del discurso histórico y donde el pasado, siguiendo a Walter Benjamin, se articula no como sucedió exactamente sino a partir del presente o "como relumbra en el instante de un peligro" (Tesis VI). Esto se observa particularmente en episodios delirantes de protagonista, en los que su esposa fallecida, Aurora, aparece encarnada en distintos cuerpos para morir de nuevo como víctima de la violencia.

\section{EN TORNO A LA MEMORIA}

Una de las primeras problemáticas que enfrenta la escritura o recuperación del pasado es la tensión entre memoria e historia, como bien señala Beatriz Sarlo:

El pasado siempre es conflictivo. A él se refieren, en competencia, la memoria y la historia, porque la historia no siempre puede creerle a la memoria, y la memoria desconfía de una reconstrucción que no ponga en su centro los derechos del recuerdo (derechos de vida, de justicia, de subjetividad). (Tiempo pasado 9)

Si bien el quehacer de la disciplina histórica busca narrar el pasado en aras de la verdad y la comprensión de éste, la objetividad de la práctica histórica ha sido cuestionada a partir de la crisis de los relatos (Lyotard). Michel De Certeau señala que la historia se erige a partir de la separación, entre pasado y presente, entre discurso y cuerpo social, planteando que el problema de la escritura de la historia es un problema de interpretación del pasado que opera a través de la exclusión tanto en el corte cronológico como en la construcción de su objeto de estudio:

El corte es pues el postulado de la interpretación (que se construye a partir de un presente) y su objeto (las divisiones organizan las representaciones que deben ser re-interpretadas). El trabajo determinado por este corte es voluntarista. Opera en el

Revista Iberoamericana, Vol. LXXIX, Núms. 244-245, Julio-Diciembre 2013, 1087-110 ISSN 0034-9631 (Impreso) ISSN 2154-4794 (Electrónico) pasado, del cual se distingue, una selección entre lo que puede ser "comprendido" y lo que debe ser olvidado para obtener la representación de una inteligibilidad presente. Pero todo lo que esta nueva comprensión del pasado tiene por inadecuado -desperdicio abandonado al seleccionar el material, resto olvidado en una explicación- vuelve, a pesar de todo, a insinuarse en las orillas y en las fallas del discurso. "Resistencias", "supervivencias" o retardos perturban discretamente la hermosa ordenación de un "progreso" o de un sistema de interpretación. Son lapsus en la sintaxis construida por la ley de un lugar, prefiguran el regreso de lo rechazado, de todo aquello que en un momento dado se ha convertido en impensable para que una nueva identidad pueda ser pensable. (La escritura de la historia 18 )

La selección, ordenación y distribución del discurso histórico necesariamente se construye sobre la base de continuidad para transformarse en una narrativa inteligible que, siguiendo a Foucault en El orden del discurso, está sujeta a mecanismos cuya función sea "conjurar los poderes y peligros, dominar el acontecimiento aleatorio y esquivar su pesada y temible materialidad"(Foucault 11, énfasis mío). Dicha materialidad manifestada en la interrupción del discurso, los silencios o los lapsus, podrían presentar posibilidades de cambio que precisamente los discursos del saber tratarán de conjurar en un movimiento de recuperación que logre sellar las fisuras. No obstante, lo residual y lo desplazado imprime su huella dejando marcas o cicatrices; mismas que el trabajo arqueológico, en un sentido foucaultiano, podría reconstruir. Dicha labor no dista mucho de la tarea que Benjamin atribuyó al materialista histórico: "pasarle a la historia el cepillo a contrapelo" (Tesis VII).

Por otra parte, si bien la memoria que ha sido cuestionada desde la disciplina histórica por carecer de un rigor metodológico y objetividad, en las recientes décadas ha cobrado un mayor interés la recuperación del pasado desde la experiencia subjetiva, ya sea por el cambio de la propia disciplina histórica que puso en el centro de su discurso la genealogía o rastros de sujetos que tradicionalmente no eran considerados actores de cambio histórico; o bien por el uso del testimonio como fuente de verdad jurídica en los procesos de reparación tras un pasado violento como fue el Holocausto o, para el caso de América Latina, las dictaduras del Cono Sur. ${ }^{1}$

Otro elemento importante que incide en el auge del pasado definitivamente es su ingreso al mercado cultural como un bien simbólico, esto se manifiesta por ejemplo en las historias de circulación masiva o los museos de tipo heritage o theme parks. ${ }^{2}$ Aunque estas tres vertientes de la memoria responden a diferentes motivaciones y agendas, las

Además del cuestionamiento que ejerció la escuela postestructuralista francesa y el nuevo historicismo de la academia anglosajona, debo mencionar la aparición de nuevas áreas de estudio que también abordaron la experiencia del sujeto y la reconstrucción del pasado desde nuevas perspectivas que, bajo el discurso de globalización y multiculturalismo, se diversificaron en estudios culturales, subalternos y postcoloniales. Véase el primer capítulo de Tiempo pasado de Beatriz Sarlo.

Revista Iberoamericana, Vol. LXXIX, Núms. 244-245, Julio-Diciembre 2013, 1087-110 ISSN 0034-9631 (Impreso) ISSN 2154-4794 (Electrónico) 
tres circulan en una época, más marcadamente durante la última década, en la cual la percepción de aceleración del tiempo amenaza con convertir el presente efímero demasiado pronto en un pasado caduco. La 'aceleración' del tiempo, sintomática a la era de la globalización, crea una sensación de amenaza de pérdida de la memoria que paradójicamente genera la proliferación de la narración y el anécdota sobre el pasado hecho que tendría los mismos efectos de aquello que Nietzsche llamó la historia anticuaria:

El sentido anticuario de un hombre, de una comunidad o de todo un pueblo posee siempre un limitadísimo campo de visión. No percibe la mayor parte de las cosas, y lo poco que ve lo ve demasiado cercano y asilado; no es capaz de medirlo y, por lo tanto, lo considera todo de igual importancia. Es decir: atribuye a lo singular una importancia excesiva. (Sobre la utilidad 63)

Si bien uno de los límites del pasado memorialista o la fetichización de la memoria es la proliferación del detalle y la creencia de que la narración pueda contener la totalidad de la experiencia traumática, en la otra cara de la moneda la incursión del sujeto en la construcción discursiva de la historia marcó una ruptura que cuestionó los principios de objetividad y verdad de la disciplina, destacando el derecho de memoria y de justicia de la voz del testigo. ${ }^{3}$

En el polo opuesto se encuentra el olvido oficial así como una serie de operaciones desde las instituciones y el manejo mediático que, en el caso del período de 'transición' tras la dictadura chilena, pretendió sellar y suturar el pasado, invisibilizar la memoria desestabilizadora de los discursos del consenso. Frente a estas 'tecnologías de la desmemoria', Nelly Richard señala:

La memoria es un proceso abierto de reinterpretación del pasado que deshace y rehace sus nudos para que se ensayen de nuevo sucesos y comprensiones. La memoria remece dato estático del pasado con nuevas significaciones sin clausurar que ponen su recuerdo

\footnotetext{
La tensión entre historia y memoria, verdad y narrativa han desencadenado una serie de debates. En la academia estadounidense de los estudios latinoamericanos la discusión ha girado en torno a la legitimida del testimonio y el papel del intelectual para mediar o representar las voces subalternas. Recuérdese lebate Stll-Bevey en tono a

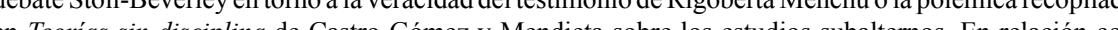

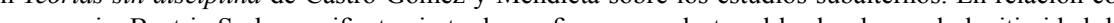
a memoria, Beatiz Sarlo manifesta cierta desconfanza y malestar al hecho de que la legitimidad del testimonio descanse sobre un discurso de reparación y de políticas identitarias convirtiendo al testimonio en un ícono de verdad y a la voz del testigo como fuente única de verdad. A lo largo de su ensayo Tiempo pasado insiste en la necesidad de distanciarse de la voz del testigo en primera persona para llevar a cabo un análisis más objetivo que eche mano de la metodología de las disciplinas sociales. Por su parte, John Beverley observa este argumento como parte del giro neoconservador de los intelectuales de izquierda, en donde el rechazo a la subjetividad en realidad es una defensa del estatus del letrado ("The Neoconservative Turn in Latin American Literary and Cultural Criticism" 73-77).
}

17. Revista Iberoamericana, Vol. LXXIX, Núms. 244-245, Julio-Diciembre 2013, 1087-1101 ISSN 0034-9631 (Impreso) ISSN 2154-4794 (Electrónico) a trabajar, llevando comienzos y finales a reescribir nuevas hipótesis y conjeturas para desmontar con ellas el cierre explicativo de las totalidades demasiado seguras de símismas. Y es la laboriosidad de esta memoria insatisfecha, que no se da nunca por vencida, la que perturba la voluntad de sepultación oficial del recuerdo mirado simplemente como depósito fijo de significaciones inactivas. ("Cita con la Violencia" 29-30)

Más que el recuento de los hechos tal y como sucedieron o la recuperación nostálgica de las voces de los testigos, me parece que la cita de Richard apunta a cuestionar la fijación de un discurso cerrado y totalizante sobre el pasado. En este sentido destaca a la memoria como una práctica o ejercicio que trabaja a partir de elementos residuales, de discontinuidades, de saberes no reconocidos, todos ellos zonas de conflicto que "guardan, en el secreto de su tensa filigrana, un saber crítico de emergencia y del rescate a tono con lo más frágil y conmovedor de la memoria del desastre” (Richard 50).

Por otro lado, en las últimas décadas, el estudio de la memoria ha despertado gran interés en la psicología y las neurociencias. Si bien la corriente evolucionista y la frenología del siglo xx tendieron a localizar la memoria en un espacio físico del cerebro, recientes estudios de las neurociencias destacan que la memoria no solamente interviene en una red de procesos que involucran diferentes áreas del cerebro, sino que el cuerpo en su conjunto encarna y moldea la memoria. Originados en el concepto de la memoria implícita de la psicología cognitiva, recientes estudios plantean una aproximación integral a la memoria corporal en donde movimiento, sensaciones, percepción, emociones y experiencia del cuerpo funcionan como núcleos de memoria. ${ }^{4}$ De estos estudios me interesa destacar, por un lado, que los procesos de memoria no necesariamente están predeterminados por la fisiología y, por otro que la memoria corporal tiene plasticidad para ajustar o resignificar experiencias previas.

The present living process reshapes its past by reshaping itself, reshaping what it was. In every living process each next bit reshapes the previous. We could say that the past reshapes itself as present living. Or, we could say that present living generates a "past" by reshaping itself. (Gendlin 74; énfasis del autor)

En este sentido, el pasado no es la única dimensión en la que habita la memoria, de tal forma que pasado y presente conviven simultáneamente como un proceso abierto, como un devenir.

Tendríamos entonces varias entradas a la memoria que, esbozadas brevemente en este apartado, se entrecruzan con los debates en torno a la objetividad-subjetividad

\footnotetext{
4 Para una tipología de la memoria corporal véase Thomas Fuchs "The Phenomenology of Body Memory" en Sabine Koch et al Body Memory, Metaphor and Movement; para un análisis desde las neurociencias véase Eric Kandel In Search of Memory: The Brain, the Mind, and the Past; y para una historia del concepto de memoria en la psicologia vease Kurt Danzinger Marking the Mind: A History of Memory.

17. Revista Iberoamericana, Vol. LXXIX, Núms. 244-245, Julio-Diciembre 2013, 1087-1101 ISSN 0034-9631 (Impreso) ISSN 2154-4794 (Electrónico)
} 
de las construcciones discursivas sobre el pasado, la legitimidad para representar el pasado, en particular, cuando entra la experiencia a un terreno que anteriormente estaba marcado por un saber científico, la incorporación del pasado al mercado de lo simbólico lo cual se traduce en la proliferación de relatos del pasado y su circulación masiva, as como el replanteamiento de la memoria como una práctica que a partir de otros saberes desmonten los relatos oficiales del pasado violento y la propuesta de la memoria corpora como un complejo proceso de resiginificaciones tanto del pasado como del presente.

En este mar de información, textos y artefactos culturales sobre el pasado se mecen sobre una cuerda floja en la que se ha vuelto difícil mantener un equilibrio entre el olvido histórico, a decir el olvido oficial, y la fetichización del pasado tanto en su vertiente conservacionista-historia monumental y anticuaria en Nietzsche-como en su vertiente nostálgica. Quien se acerque a estos temas habrá de ser tan cuidadoso como un equilibrista, ya que ambos el olvido y la fetichización se ciernen como un vacío en el cual se puede caer en cualquier momento. Si bien el olvido ha sido la tendencia general desde los discursos institucionales del Estado o lo que llamaríamos la historia oficial, la monumentalización de la historia al igual que su ingreso a un mercado de lo simbólico tienden en esencia a fijar el pasado, a clausurar un diálogo crítico y neutralizar las posibilidades de cambio. Dichas tendencias, aunque en polos opuestos, no distan mucho de crear a la larga efectos similares de borramiento. No obstante, la memoria en tanto práctica emerge una y otra vez para señalar el pasado soslayado.

\section{LAS MEMORIAS DEL 68}

Indudablemente los trágicos eventos en Tlatelolco que dieron la estocada final al movimiento estudiantil del 68 marcaron un hito en las prácticas políticas de la sociedad civil mexicana. Sin embargo, la memoria oficial fijó al movimiento del 68, en el mejor de los casos, como un lejano mito de la edad de oro al cual se regresa por nostalgia o, en el peor de los casos, al silencio. Por su parte, la respuesta de la mayor parte de los intelectuales fue contundente tras la masacre de Tlatelolco, ejemplo de ello fue la renuncia de Octavio Paz a su cargo diplomático en la India, los poemas, cartas y declaraciones de diferentes generaciones de escritores y poetas publicados en el suplemento La cultura en México, así como los escritos de José Revueltas desde la prisión de Lecumberri. Además de la producción poética, el ciclo de la narrativa tlatelolca comenzó con textos testimoniales y ensayísticos que buscaron llenar el vacío provocado por la censura y el

\footnotetext{
Algunos intelectuales de la generación de la Revolución estuvieron alineados con la versión oficial del gobierno como por ejemplo: Mariano Azuela, Luis Martín Guzmán, Salvador Novo y Agustín Yañez por mencionar algunos.
} ISSN 0034-9631 (Impreso)

1. LXXIX, Núms. 244-245, Julio-Diciembre 2013, 1087-110 ISSN 2154-4794 (Electrónico) silencio de los medios. ${ }^{6}$ Por otro lado, surgieron otros textos que abierta o sesgadamente cuestionaron la legitimidad del movimiento estudiantil y la magnitud de la masacre transformando el espacio literario en una 'nueva' arena política.?

Junto con el recuento testimonial surgieron también una serie de debates que giraron grosso modo en torno a 1) lo literario y la función del intelectual (literatura de compromiso versus literatura de creación), 2) a la tradición o ruptura de la narrativa del 68 en contraste con la literatura anterior, y 3 ) la catalogación o periodización de la literatura pos- $68 .{ }^{8} \mathrm{Si}$ bien estos debates fueron consecuencia, en cierta medida obvia, del campo de lo social, del impacto que tuvo la represión, así como de la censura en los medios y sobre todo de la impunidad, por otro lado, se puede observar que la memoria del 68 ha tenido una transición de la indignación de las primeras décadas a la desarticulación del pensamiento de izquierda como una posibilidad truncada desde su origen y destinada al fracaso, lectura sintomática que emerge a finales de la década de los ochenta. ${ }^{9}$ De este modo podríamos señalar de manera general distintas construcciones de la memoria del 68 -y algunos ecos de la guerrilla- que se entrecruzan tanto en el ámbito social y político, como en el literario: 1) la construcción que presenta el recuerdo del 68 como la edad de oro destacando, entre la nostalgia y la monumentalización, el fracaso del movimiento, 2) la que destaca la necesidad de un cierre a través del saneamiento o deslinde

6 Por ejemplo Postdata (1970) de Octavio Paz y Tiempo mexicano (1971) de Carlos Fuentes y los textos de José Revueltas recompilados posteriormente en Mexico 68: Juventud y Revolución (1978). Cabe destacar muchos de los textos producidos tanto por intelectuales o participantes del movimiento son textos híbridos que se encuentran entre el testimonio, la crónica o la reflexión ya sea autobiográfica exás Además de los textos bastante conocidos de Elena Poniatowska, La noche de Tlatelocico

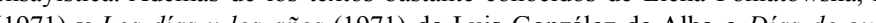
(1971) y Los dias y los años (1971) de Luis González de Alba o Dias de guardar (1970) de Carlos Monsiváis, también se encuentran Tres culturas en agonía (1969) de Jorge Carrión y Daniel Cazés, Tiempo de hablar 1970 José Revueltas, Arturo Álvarez Garín y Eduardo Valle, T-68 (1971) de Juan Miguel de Mora, El movimiento estudiantil del 68,(1972) de Ramón Ramírez por citar algunos ejemplos. Por ejemplo el libelo anónimo El móndrigo (1968) que, en la forma de diario falso de un miembro del $\mathrm{CNH}$, destacó al movimiento como un complot orquestado bajo la influencia de fuerzas extranjeras y con fines políticos electorales, versión que justamente coincidía con la postura oficial del gobierno. Esta versión también aparece en las novelas Juegos de invierno (1970) de Rafael Solana o La plaza (1971) de Luis Spota.

8 Para un seguimiento de los debates sobre la autonomía intelectual véase Volpi La imaginación y el poder (capítulo V) y Patricia Cabrera Una inquietud de amanecer (163-76). Sobre la ruptura formal de la narrativa post-68 véase Brushwood, Franco, Herz, Long y Medina, sobre el retorno a la tradición social narrativa post-68 véase Brushwood, Franco, Herz, Long y Medina, sobre el retorno a la tradición social
véase Sefchovich y sobre la periodización de la "narrativa tlatelolca" véase Cabrera "La narrativa del 68 véase Sefchovich y sobre la periodizacion de la "nes de los años", López, Martré y Medina.

a través de los años", López, Martré y Medina.
Irene Fenoglio señala que tanto en La guerra de Galio (1991) de Héctor Aguilar Camín como en El Irene Fenoglio señala que tanto en La guerra de Galio (1991) de Héctor Aguilar Camín como en El
fin de la locura (2003) de Jorge Volpi las secuelas del 68 aparecen como un proyecto fallido desde su fin de la locura (2003) de Jorge Volpi las secuelas del 68 aparecen como un proyecto fallido desde su inicio justificando entonces el abandono las políticas culturales, económicas y sociales. De este modo lo revolucionario "se expone como una sinrazón, una locura o una inmadurez, la crítica de la izquierda entre en una 'madurez' representada por el neoliberalismo" ("La nueva ficción de la izquierda"18).

27. Revista Iberoamericana, Vol. LXXIX, Núms. 244-245, Julio-Diciembre 2013, 1087-1101 ISSN 0034-9631 (Impreso) $\quad$ ISSN 2154-4794 (Electrónico) 
de los radicalismos para avanzar por la vía democrática, confinando al movimiento a un período de formación o un error de juventud; 3) la clausura de la memoria que, ligada a la anterior, inocula estratégicamente amnesia a través de las tecnologías de la desmemoria, a decir los medios y la historiografía oficial; 4) aquella que retoma los sucesos del movimiento estudiantil o la guerrilla como un vago referente epocal para trazar una genealogía de la violencia ligada a la actual sociedad de consumo, es decir el narcotráfico $;^{10}$ y 5) aquella que presenta a la memoria como un pasado abierto en constante interacción con el presente y que particularmente se manifiesta en las calles.

\section{LA MEMORIA EN LA MARGEN}

Perteneciente al ciclo de la narrativa tlatelolca, Muertes de Aurora (1980) de Gerardo de la Torre ha sido una novela reconocida por abordar el 68 desde la perspectiva obrera; sin embargo, a pesar de haber sido editada en cuatro ocasiones su prosa ha sido escasamente valorada, como señala Domínguez Michael (Antología de la narrativa mexicana del siglo $X X$, Tomo II, 592). A comienzos de la década de los ochenta la narrativa del 68 había agotado el discurso testimonial y parecía que los textos habían quedado atrapados entre el silencio impuesto del Estado y el obsesivo recuento de la tarde fatídica del 2 de octubre.

En este sentido la novela Muertes de Aurora se distancia de la narrativa anterior ya que trabaja a partir de diversos elementos residuales para hacer un recuento de una memoria que quedó al margen. La experiencia obrera es incorporada no sólo a nivel temático, sino que el foco de narración muestra la visión de mundo de los obreros en donde el movimiento del 68 aparece como una posibilidad para resucitar las demandas laborales que habían quedado pendientes diez años atrás. Asimismo lo residual aparece como elemento crucial en la novela ya que el testigo del pasado y depositario de la memoria de violencia es el personaje menos fidedigno, un hombre alcohólico y despolitizado que al final de la novela mendiga por las calles de la ciudad.

La novela abarca los tres meses que duró el movimiento estudiantil dando un seguimiento relativamente cronológico. Diferentes líneas narrativas están entrelazadas a partir de una historia eje en donde un grupo de obreros petroleros cobra conciencia de las dimensiones del movimiento y la represión del Estado. Efrén, Arturo y Galdino cansados de una cotidianidad agobiante y de un sindicato corrompido deciden revivir una pequeña célula de resistencia que logre politizar a los compañeros para unirse al movimiento estudiantil del 68. Efrén contacta a Jesús de la Cruz, antiguo trabajador petrolero que participó en la huelga obrera del 58 . No obstante, tras la derrota del movimiento obrero y la

${ }_{10}$ En las novelas de Elmer Mendoza -Un asesino solitario (1999) y particularmente El amante de Janis
Joplin (2001)-aparece el eco del 68 y la guerrilla, destacando el vínculo entre la violencia de ésta última y el narcotráfico.

Revista Iberoamericana, Vol. LXXIX, Núms. 244-245, Julio-Diciembre 2013, 1087-1101 ISSN 0034-9631 (Impreso) $\quad$ ISSN 2154-4794 (Electrónico) muerte de su esposa Aurora, Jesús de la Cruz ha caído en completa apatía y en el alcohol. Después de tener varios empleos como mecánico y tornero en la refinería de Petróleos Mexicanos (PEMEX), de ser traductor para una agencia de noticias y finalmente vender enciclopedias y libros a domicilio, su alcoholismo lo lleva al borde social y al comienzo del movimiento está prácticamente desempleado. Las historias paralelas se desarrollan en torno a los lugares de trabajo de Jesús de la Cruz, por un lado las historias de los obreros de la refinería y por otro lado la historia de Marco Lépido, antiguo compañero de Jesús en la agencia de noticias que cree fervientemente en su ascenso social si logra acuñar la frase política perfecta. Por otro lado, se desarrolla la historia de María, la novia de Galdino, que a los quince años es madre soltera, enfrenta una cotidianidad abrumadora que parece no tener futuro y se resiste a tomar responsabilidad por su hijo al cual la novela se refiere como "El innombrado". Tras la muerte de "El innombrado", María viaja con unos amigos a Veracruz, donde es violada y abandonada.

Aunque los personajes no participan en el mitin del 2 de octubre, sus vidas sufren un giro trágico después de la represión que los lleva al descenso o al conformismo. La narración se distancia de la épica y romantización del movimiento al enfatizar la opresión de lo cotidiano que, junto con la represión del Estado, quiebran al sujeto, lo territorializan y lo obligan a asumir una posición dentro del establishment, a la cual Jesús se resiste. Si bien los intentos politizados de esta resistencia han sido desarticulados, parece que la novela opta por la fuga o desterritorialización del sujeto a través del alcohol y el delirio de Jesús de la Cruz.

La participación de los obreros de PEMEX en el movimiento del 68, aunque proporcionalmente poca, es emblemática por varias razones, en primer lugar porque PEMEX simbolizó la emancipación nacional y fue un producto tangible del triunfo de la Revolución mexicana. En segundo lugar porque efectivamente fue la primera fuente económica del país en esa época y porque a su vez ha sido uno de los sindicatos más corruptos. La lucha por un sindicalismo independiente fue profundamente afectada por el sistema corporativista de los sindicatos oficiales -0 sindicatos charros- alineados con el PRI. ${ }^{11}$ Las huelgas o manifestaciones eran controladas con fines políticos que beneficiaran al gobierno o a los líderes, y los intentos de representación independiente eran inmediatamente desmantelados mediante el soborno o la represión abierta como ocurrió con el movimiento obrero de 1958. Por otro lado, cabe recordar que una de las

\footnotetext{
"La novela aborda una historia crítica del sindicalismo en México y particularmente destaca los privilegios y corrupción del sindicato de PEMEX. Existen muchos elementos autobiográficos ya que el mismo Gerardo de la Torre trabajó en PEMEX y participó en el movimiento del 68. De la Torre señala que la participación se limitó a dos secciones de la refinería de Azcapotzalco que de ser un pequeño de 12 obreros en la manifestación del 13 de agosto logró reunir a 500 trabajadores en la manifestación del 13 de septiembre. Los mítines entre estudiantes y obreros a las puertas de la refinería comenzaron con 200 30 trabajadores, pero en poco tiempo se multiplicó hasta 150 trabajadores ("Los petroleros en el 68").
}

Revista Iberoamericana, Vol. LXXIX, Núms. 244-245, Julio-Diciembre 2013, 1087-1101 ISSN 0034-9631 (Impreso) ISSN 2154-4794 (Electrónico) 
demandas del pliego petitorio del movimiento estudiantil del 68 fue la liberación de los presos políticos -en su mayoría líderes obreros que intentaron romper con la hegemonía de los sindicatos oficiales por ejemplo Vallejo, Campa y Othón Salazar entre otros.

La novela destaca la dificultad para organizar reuniones y repartir volantes de manera clandestina bajo la fuerte supervisión y control del propio sindicato petrolero. De este modo, las condiciones para el obrero fueron más severas en contraste con los modos de operación del sector estudiantil. No obstante, la novela dista mucho del tono solemne y la situación de control y espionaje es parodiada a través del personaje Abundio Rosales. Como empleado de confianza, Rosales decide convertirse en espía e informante de las autoridades sindicales, como una forma de arribismo o ascenso social, al descubrir en los vestidores un volante que llamaba a los petroleros a unirse al movimiento estudiantil:

¡Eso en la refinería no! Los trabajadores petroleros podían ser groseros, borrachos, a veces irresponsables, pero también eran agradecidos y no iban a dejarse arrastrar por la canalla estudiantil que se enfrentaba a las autoridades. (Muertes de Aurora 33)

A su vez la novela aborda la cita fallida entre el sector obrero y universitario como resultado de los mecanismos de cooptación de los sindicatos y por la ausencia de un lenguaje común. La apropiación de las marchas por parte de los trabajadores, así como el intercambio en los mítines afuera de la refinería creó un espacio de solidaridad, sin embargo la novela destaca tanto en los encuentros entre obreros y estudiantes, como en las células de Partido Comunista Mexicano, una distancia educativa y en bastante medida la poca funcionalidad teórica de la izquierda. Por ejemplo en un pasaje de la novela, ante las pretensiones de los estudiantes del IPN de politizar y educar a los obreros uno de los trabajadores contesta:

-Dígame compañero. -Hágame el favor de prestarme ese librito [la Constitución] maestro, y si puede, regálenos uno a cada uno, porque si como usted dice, es tan bueno y tan sagrado, pues vamos saliendo a la calle cada quien con el suyo y cuando el granadero o el soldado nos quiera arrear un culatazo o una patada, le enseñamos el librito y se acabó. (Muertes de Aurora 86)

Se puede observar por un lado, los encuentros y desencuentros entre la ciudad letrada y la ciudad real; es decir, si la Constitución prevé un orden social y estado de derecho en el que se garantizan los derechos ciudadanos, existe otro orden de facto impuesto por la fuerza pública. Por otro lado, se puede observar el asalto a la ciudad letrada a través de los diversos usos de la letra por parte de sujetos no educados o no pertenecientes a este grupo y que de diversos modos intentan apoderase de ésta. La escritura en la novela cobra un papel fundamental como una práctica que desborda los límites de aquello que se considera literario o bien como un uso correcto de la letra. Los

Revista Iberoamericana, Vol. LXXIX, Núms. 244-245, Julio-Diciembre 2013, 1087-110 ISSN 0034-9631 (Impreso) ISSN 2154-4794 (Electrónico) volantes de los petroleros redactados con faltas de ortografía, los reportes de Rosales a la dirección del sindicato, los intentos de Jesús de la Cruz para escribir historias que de algún modo son parte de la novela, o bien las cartas de amor de Marco Lépido parecen imitaciones ingenuas o torpes en el manejo del discurso escrito que precisamente enfatizan el carácter discriminatorio de las diferencias educativas. ${ }^{12}$ Por otro lado, la novela parodia el desgaste del discurso político. Marco Lépido, que sueña con acuñar la frase política para subir en el escalafón burocrático, desarrolla una técnica que consiste recopilar frases políticas de moda y combinarlas:

La lucha politica es el aumento de las exportaciones. Elevar los niveles de vida del mexicano es prolongar en la lucha política la lucha social.

La prolongación de las exportaciones eleva la lucha política, significa lucha social, no es sino el aumento de los niveles de vida del mexicano.

La lucha por la vida eleva los niveles politicos de las exportaciones, es la prolongación del mexicano, significa el aumento social. (Muertes de Aurora 42)

El método obviamente fracasa y si bien las frases dejan de tener un sentido, tampoco distan mucho de la demagogia política. Tras la masacre de Tlatelolco, la frase acuñada por Marco Lépido es "La patria es primero" y junto con la frase que cierra la novela: "El trabajo ennoblece", de la Torre denuncia cómo la represión de Estado fue justificada por dos ejes fundamentales: productividad y nacionalismo.

\section{LA MEMORIA DELIRANTE}

Como se mencionó al comienzo, Muertes de Aurora se aleja de la memoria como una reconstrucción minuciosa de los hechos o como testimonio que busque establecer la verdad. A pesar de que las historias se enmarcan en el periodo que duró el movimiento estudiantil, la narración no sigue un orden cronológico, comienza in media res y por lo menos en la primera parte de la novela hay constantes retrospecciones en el tiempo que en forma de círculos retardan el momento del encuentro entre los petroleros y Jesús de la Cruz. La memoria y el olvido están estrechamente vinculados como dos caras de la misma moneda, sin embargo la memoria aparece solamente durante los estados alterados como espacios aislados o pequeñas islas en medio de la cotidianidad. Tras la muerte de su esposa, Jesús de la Cruz se refugia en el alcohol como una forma de olvidar la pérdida; no obstante el alcohol funciona como detonante de la memoria. Por otro lado, la invitación para ayudar a los petroleros y unirse al movimiento del 68

12 En la novela se destaca la contradicción del grupo intelectual que participó en el movimiento, mientras

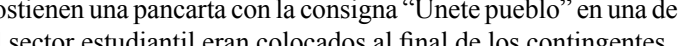

Revista Iberoamericana, Vol. LXXIX, Núms. 244-245, Julio-Diciembre 2013, 1087-1101 ISSN 0034-9631 (Impreso) ISSN 2154-4794 (Electrónico) 
hace renacer la esperanza en Jesús como una voluntad de memoria que pueda reparar o rescatar las luchas pasadas:

La amnesia, el olvido. Bebía para borrar el pasado y al mismo tiempo olvidaba todo género de recomendaciones. Después se empeñaba en el rescate de un gesto, de una frase, de una imagen, de un sentimiento. [...] Pudo decir por teléfono beban beban beban y déjenme en paz. Pudo haber mencionado su alcoholismo, ese mundo aparte donde nada sabemos de conciencia, principios de clase, lucha de clases, capital, beban y olviden todo, no vale la pena. Pero nada de eso dijo. Aceptó la cita, se dispuso a ejemplificar con embriaguez desnuda y silenciosa. Quiero que me digan, que me ayuden a recordar. Y Jesús de la Cruz, de nuevo comenzó a recordar. (Muertes de Aurora 16-17)

El trabajo de memoria en Muertes de Aurora superpone la memoria del 68 con la memoria de luchas pasadas engarzando varias dimensiones del pasado que comparten una constante de represión y violencia. Si bien Jesús de la Cruz tiene la voluntad de recuperar la memoria, en realidad es el personaje menos politizado y su deseo de recorda no es suficiente para participar activamente en el movimiento. De este modo la memoria voluntaria queda segada y es precisamente a través de una memoria involuntaria, una memoria corporal activada a través de los estados alterados, que el pasado de violencia emerge y se despliega frente a él convirtiéndolo en un testigo o ángel de la historia.

La reconstrucción del pasado se lleva a cabo en dos planos: mientras el primero sigue relativamente la cronología del movimiento estudiantil desde la margen, el segundo aborda la memoria de violencia como un flujo que aparece solamente durante el delirium tremens del protagonista. Mientras las historias de los personajes siguen una secuencia paralela al desarrollo del movimiento estudiantil, la historia de Jesús y en especial los episodios alucinatorios rompen con esta secuencia cronológica o lineal. Junto con las retrospecciones de la narración, la repetición de las escenas en la cantina o en su departamento durante la borrachera reproducen narrativamente el efecto del alcohol, el pensamiento circular y el delirio creando un espacio otro en el cual emerge la memoria.

La irrupción de la memoria como un flujo incontenible desarticula narrativamente la continuidad del relato y a su vez la continuidad del concepto del pasado al enlazar distintos momentos de violencia, aparentemente inconexos, que cobran forma en las alucinaciones de las diferentes muertes de Aurora. Las apariciones de Aurora ocurren durante los episodios de delirio, entre moscos, aves, vampiros y chinches que atacan a Jesús, Aurora aparece al final como un pasado soslayado que emerge de entre las ruinas y presenta la posibilidad de un cambio. Sin embargo Aurora muere una y otra vez en distintas circunstancias. En la primera muerte Aurora encarna a una estudiante durante una manifestación que es asediada por la policía, en la segunda muerte Aurora perece durante el bombardeo a una aldea en Vietnam, en la tercera alucinación muere en las cárceles clandestinas a manos de la policía política: ISSN 0034-9631 (Impreso) ISSN 2154-4794 (Electrónico)
Aurora desnuda, arrastrada en tenebrosos pasillos por dos policías vestidos de civil. Vas a decir todo lo que sepas, desgraciada cabrona. [...] El hombre se levantó y dejó caer los puños sobre el rostro infantil; supo que sus puños no hacían daño después de la violación frecuente, los manguerazos en los riñones, la picana en la vagina y en el recto, las dentelladas en los pezones, la risa y los insultos. [...] Los hombres se dieron cuenta de que se les escapaba el cuerpo, el cuerpo delgadito y maltratado de Aurora, y se echaron sobre él endemoniados. Los [sic] sostenían por los miembros, tiraban de él, pero el cuerpo se iba, más fuerte su voluntad de desaparecer que el vigor y la violencia que lo retenían. (Muertes de Aurora 109-110)

En su cuarta aparición Aurora encarna a una esclava fugitiva que es perseguida y devorada por los perros de caza, y en la última aparición Aurora muere durante el parto, que es la versión más cercana a lo que sucedió en realidad. Sin embargo, quiero destacar que en la novela el manejo de una memoria delirante y múltiple desarticula la fijación del pasado como una verdad unívoca o totalizante. Existen tantas versiones de la muerte de Aurora como de la masacre de Tlatelolco o cualquier otro evento de violencia. No obstante ese pasado, parafraseando a Benjamin, no consiste en reconstruirlo tal y como sucedió, sino en apropiárselo en el momento en que relumbra en el instante del peligro. La novela destaca cómo el movimiento del 68 fungió como esperanza de luchas pasadas y la amenaza que se cernió sobre ese presente trajo consigo memorias de violencia pasada.

La evocación de los elementos residuales que no fueron incorporados a la narrativa del 68 , es decir las condiciones de los sindicatos para participar en el movimiento, as como las diferencias entre sector educado y obrero, demarcan una memoria descentrada. A su vez la multiplicidad de la imagen de Aurora incorpora la represión del movimiento estudiantil como síntoma o secuela de una violencia programática y continua que recorre la cacería de esclavos prófugos en el deep south de Estados Unidos a la guerra de Vietnam y las sesiones de tortura por parte de la policía política en cualquier parte del mundo.

Las memorias individuales, memorias residuales y olvidadas se fusionan en una memoria colectiva que solamente es capaz de recuperar un espacio fuera de la 'realidad', a decir de la historia oficial. La multiplicación de versiones, así como de cuerpos y escenarios en que Aurora habita, reaparece y muere parece señalar que la memoria como residuo retorna una y otra vez pese a ser absorbida y territorializada por el signo. Aurora es la memoria que regresa una y otra vez, como un ave Fénix que emerge de sus cenizas. Más lo importante no es preguntar por qué se repite, sino qué es lo que señala su incómoda presencia, a decir la violencia de Estado frente a la cual Jesús no es más que un ángel caído de la historia.

Revista Iberoamericana, Vol. LXXIX, Núms. 244-245, Julio-Diciembre 2013, 1087-1101 ISSN 0034-9631 (Impreso) ISSN 2154-4794 (Electrónico) 


\section{BiBLIOGRAFÍA}

Benjamin, Walter. "Para la crítica de la violencia". Ensayos escogidos. H. A. Murena trad. México: Ediciones Coyoacán, 1999. 109-30.

"Tesis de filosofía de la historia". Discursos interrumpidos I. Jesús Aguirre, trad Suhrkamp Verlag 1972. Madrid: Taurus, 1973. 175-92.

Beverley, John. "The Neoconservative Turn in Latin American Literary and Cultura Criticism." Journal of Latin American Cultural Studies 17/1 (2008): 65-83.

Brushwood, John S. La novela mexicana: 1967-1982. México: Grijalbo, 1985.

Cabrera López, Patricia. "La narrativa del 68 a través de los años: Debate literario y político". Memoria, ficción y realidad en América Latina. $2^{\circ}$ Congreso Internacional Entrecruzamientos en la América Hispana. México: UAM Azcapotzalco/ Universidad de Alicante/ Secretaría de Hacienda y Crédito Público, 2010.

"Novelas políticas de los años setenta en México". Pensamiento, cultura y literatura en América Latina. Patricia Cabrera López, ed. México: Centro de Investigaciones Interdisciplinarias en Ciencias y Humanidades/UNAM/Plaza y Valdés, 2004. 263-90.

Una inquietud de amanecer: Literatura y política en México 1962-1987. México: CEIICH/UNAM/Plaza y Valdés, 2006.

Certeau, Michel de. La escritura de la historia. L'ecriture de l'historie. 1978. Jorge López Moctezuma, trad. 2 ed. México: Universidad Iberoamericana, 1993.

Danziger, Kurt. Marking the Mind: A History of Memory. Cambridge: Cambridge UP, 2008.

Fenoglio, Irenre. "La nueva ficción de la izquierda en México". Marx and Marxism's in Latin America. Ithaca: Cornell UP, 2007.

"Ésa era, ay la Revolución: la teoría como desmontaje de la política en El fin de la locura de Jorge Volpi”. Revista de Literatura Mexicana Contemporánea 37/14 (2011): 63-72.

Foucault, Michel. El orden del discurso. L'ordre du discurs. 1970. Alberto González Troyano, trad. Buenos Aires: Tusquets, 1992.

Franco, Jean. "The Critique of the Pyramid and Mexican Narrative after 1968." Latin American Fiction Today. Rose S. Minc y Takoma Park, eds. New Jersey: Hispamérica, 1979. 46-60.

Gendlin, Eugene T. "Comment on Thomas Fuchs: The Time of the Explicating Process." Body Memory, Metaphor and Movement. Sabine Koch et al. Amsterdam: John Benjamins, 2012.

Herz, Theda M. "Mexican Fiction in the 1970's and the Critical Controversy on Artistry versus Significance.” Revista Canadiense de Estudios Hispánicos 13/1 (1988): 67-78.

Kandel, Eric R. In Search of Memory: The Emergence of a New Science of Mind. New York: WW Norton \& Company, 2006.

Revista Iberoamericana, Vol. LXXIX, Núms. 244-245, Julio-Diciembre 2013, 1087-1101 ISSN 0034-9631 (Impreso) ISSN 2154-4794 (Electrónico)
Koch, Sabine C. et al. Body Memory, Metaphor and Movement. Amsterdam: John Benjamins, 2012.

Long, Ryan F. Fictions of Totality: The Mexican Novel, 1968, and the National-Popular State. West Lafayette: Purdue UP, 2009.

López González, Aralia. La narrativa tlatelolca. México: UAM Iztapalapa, 1987.

Martré, Gonzalo. El movimiento popular estudiantil de 1968 en la novela mexicana. 1986. México: UNAM, 1998.

Medina, Rubén. "Ayer es nunca jamás: continuidad y ruptura en la narrativa mexicana del 68”. Revista de Crítica Literararia Latinoamericana 21/42 (1995): 207-18.

Monsiváis, Carlos. "Persistencia de la memoria" Parte de Guerra II. Los rostros del 68. Julio y Carlos Monsiváis, Scherer García, ed. México: Nuevo siglo/Aguilar, 2002. 26-40.

Nietzsche, Friedrich. Sobre la utilidad y el perjuicio de la historia para la vida. Germán Cano, trad. Madrid: Biblioteca Nueva, 1999.

Richard, Nelly. Residuos y metáforas. Ensayos de crítica cultural sobre el Chile de la Transición. Santiago: Editorial Cuarto Propio, 1998.

Sarlo, Beatriz. Tiempo pasado: cultura de la memoria y giro subjetivo. Una discusión. Buenos Aires: Siglo XXI, 2005.

Sefchovich, Sara. "Una sola línea: la narrativa mexicana". Literatura mexicana hoy: del 68 al ocaso de la revolución. Karl Kohut, ed. Madrid/Frankfurt: Iberoamericana/ Vervuert, 1991. 47-54.

Teichmann, Reinhard. De la onda en adelante. Conversaciones con 21 noveslitas mexicanos. México: Posada, 1987.

Torre, Gerardo de la. Muertes de Aurora. 1980. México: Coordinación de Difusión Cultural UNAM, 1991

"Los petroleros en el 68". La palabra y el hombre 4/68 (1998): 121-31.

Trejo Fuentes, Ignacio. "La novela mexicana de los setentas y ochentas". Literatura mexicana hoy. Del 68 al ocaso de la revolución. Karl Kohut, ed. Madrid/Frankfurt Iberoamericana/Vervuert, 1991. 55-65.

Volpi, Jorge. La imaginación y el poder: una historia intelectual de 1968. México: Era, 1998.
Revista Iberoamericana, Vol. LXXIX, Núms. 244-245, Julio-Diciembre 2013, 1087-1101 ISSN 0034-9631 (Impreso) 
